\title{
The prevalence of pre-hypertension and its association to established cardiovascular risk factors in south of Iran
}

\author{
Karamatollah Rahmanian ${ }^{1}$ and Mohammad Shojaie ${ }^{2^{*}}$
}

\begin{abstract}
Background: Pre-hypertension is associated with an increased risk of the development of hypertension and subsequent cardiovascular disease and raises mortality risk. The aim of this study was to determine the prevalence of pre-hypertension and to explore the associations between pre-hypertension and established cardiovascular risk factors in a population-based sample of Iranian adults.

Methods: In this cross-sectional study a representative sample of 892 participants aged $\geq 30$ years was selected using a multistage cluster sampling method. After completion of a detailed demographic and medical questionnaire (gender, age, history of diabetes mellitus and hypertension, taking antihypertensive or hypoglycemic agents and history of smoking), all participants were subjected to physical examination, blood lipid profile, blood glucose, anthropometric and smoking assessments, during the years 2009 and 2010. Variables were considered significant at a $p$-value $\leq 0.05$. Statistical analysis was performed using SPSS version 11.5 software.

Results: Pre-hypertension was observed among 300 (33.7\%) subjects, 36.4\% for men and 31.4\% for women $(p>0.05)$. The pre-hypertensive group had higher levels of blood glucose and triglycerides, higher body mass index and lower percentage of smoking than did the normotensive group. Multivariate logistic regression analysis showed that obesity and overweight were the strongest predictors of pre-hypertension [odds ratio, $2.74: 95 \% \mathrm{Cl}$ (Confidence Interval), 1.62 to $4.62 \mathrm{p}<0.001$; odds ratio, $2.56,95 \% \mathrm{Cl}, 1.74$ to $3.77, \mathrm{p}<0.001$ respectively].

Conclusions: Overweight and obesity are major determinants of the high prevalence rate of pre-hypertension detected in Iranian population. Therefore, primary prevention strategies should concentrate on reducing overweight and obesity if the increased prevalence of pre-hypertension is to be diminished in Iranian adults.
\end{abstract}

Keywords: Pre-hypertension, Cardiovascular risk factor, Obesity, BMl

\section{Background}

High blood pressure is an important subject in primary care in the 21st century and has become growing worldwide, especially in developing countries [1]. Furthermore, hypertension is one of the most important health problems because of its relation to ischemic heart disease, which is the leading cause of death [2]. The prevalence of hypertension is $8-14 \%$ in population, worldwide [3]. In Iran, the Iranian Health Profile Survey (IHPS) of 1999 reported a hypertension prevalence of $12.54 \%$ in

\footnotetext{
* Correspondence: Shojaie1300@yahoo.com

${ }^{2}$ Department of Internal medicine, Jahom University of Medical Sciences, Motahhari Avenue, Jahrom, Iran

Full list of author information is available at the end of the article
}

adults older than 30 years [4]. High blood pressure and its complications is a significant problem and cardiovascular diseases are the most common cause of death in Iran [5]. Many of studies on different populations have identified certain factors such as older age, hypercholesterolemia, diabetes mellitus and increased body mass as being associated with high blood pressure [2,6,7]. The last years, some researchers have documented an increase in the risk of cardiovascular disease in subjects with systolic blood pressures (SBP) between $120-139 \mathrm{mmHg}$ and/or diastolic blood pressures (DBP) between $80-89 \mathrm{mmHg}$ $[8,9]$. Based on this current evidence, the Seventh Report of the Joint National Committee (JNC7) on Prevention, Detection, Evaluation and Treatment of High Blood

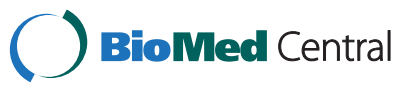


Pressure recommended a new classification of blood pressure level under the term pre-hypertension [6].

Pre-hypertension is associated with an increased risk of the development of hypertension and subsequent cardiovascular disease and raises mortality risk [10-13]. There are additional reports of prevalence percentages for pre-hypertension, with estimates ranging from 30 $48.9 \%[6,7]$.

The aim of the present study was to estimate the prevalence of pre-hypertension and to examine its association with established cardiovascular risk factors (i.e. overweight, obesity, hypercholesterolemia, diabetes mellitus and smoking) from a population-based study of Iranian adults, in order to propose primary preventive strategies for combating it.

\section{Methods}

\section{Study participants}

The present investigation adopted a cross-sectional design protocol. The population studied - a multi-stage stratified clustering sample - was derived from a patient cohort from ten urban health centers operating in Jahrom City in the South region of Iran. Pregnant and lactating women and/or persons with chronic disease and mental disorders and unable to walk, were excluded. The final sample consisted of 405 males (aged $51.9 \pm 13.9$ years) and 487 females (aged $48.5 \pm 12.9$ years) All subjects (892) answered a demographic and a detailed medical questionnaire.

Afterwards, they were subjected to anthropometric, blood pressure and fasting blood glucose and lipid profile measurements. All data were collected during the years 2008 and 2009.

Identical standard protocols were used for each measurement conducted by trained physician. Signed informed sanction was obtained from all participants and Ethical approval was obtained from the Ethics Committee of the Jahrom University.

\section{Instruments and measurements Demographic and medical questionnaire}

This includes the demographic and medical records of patients about "gender, age, history of diabetes mellitus and hypertension, taking antihypertensive or hypoglycemic agents.

\section{Smoking status assessment}

Smoking status was ascertained by means of a questionnaire. Subjects, who smoked one or more cigarettes or one cup of water pipe per week, were considered as smokers.

\section{Anthropometry}

Body weight was measured (Seca 700, Germany) to the nearest 100 grams, with light cloth and without shoes.
Height was measured to the nearest $0.5 \mathrm{~cm}$, without shoes using a stadiometer (Seca 700, Germany). Body mass index (BMI) was calculated as weight (in kilograms) divided by height (in meters) squared.

\section{Blood pressure}

Blood pressure was measured after the subject had rested for at least 5 minutes and from right arm placed at the heart level by a physician. Two measurements were taken by a mercury sphygmomanometer (Richter, Germany) with at least 5 minutes between successive measurements. The mean of two measurements of Korotkoff phase I was recorded for systolic blood pressure (SBP). The mean of two values of Korotkoff phase IV was recorded for diastolic blood pressure (DBP). Prehypertension was defined as having either a SBP of 120 to $139 \mathrm{mmHg}$ and/or DBP of 80 to $89 \mathrm{mmHg}$, according to JNC7, in persons who were not on antihypertensive medication [14]. Hypertension was defined as an average SBP $\geq 140 \mathrm{mmHg}$, an average $\mathrm{DBP} \geq 90 \mathrm{mmHg}$, and/or self reported current treatment for hypertension with antihypertensive medication.

\section{Serum assessments}

Venous blood was collected in the morning after an overnight fast and serum was used for the biochemical tests. Diabetes mellitus was defined as having two fasting serum glucose assessment of equal to or more than $126 \mathrm{mg} / \mathrm{dl}$ or being on treatment for diabetes [15]. Dyslipidemia was defined according to ATP III report [16]. Hypercholesterolemia was defined as fasting total serum cholesterol of greater than or equal to $240 \mathrm{mg} / \mathrm{dl}$. Blood concentration of LDL-C (low-density lipoprotein cholesterol) equal or above $160 \mathrm{mg} / \mathrm{dl}$ and blood concentration of HDL-C (high-density lipoprotein cholesterol) under $40 \mathrm{mg} / \mathrm{dl}$ respectively, were considered to be undesirable.

\section{Statistical analysis}

For statistical analysis the BMI $\left(\mathrm{kg} / \mathrm{m}^{2}\right)$ was classified into two categories: overweight: $25-29.9$ and obese: $\geq 30.0$. Continuous variables were presented as mean values and standard deviation. Categorical variables were presented as frequencies. Associations between categorical variables were tested by the use of contingency tables and the chi-square test. Independent $T$-test was used to comparisons between continuous variables and blood groups (hypertension or pre-hypertension with normal blood pressure). Binary logistic regression was used to assess the association of age, gender, smoking and anthropometric and serum parameters to blood pressure (pre-hypertension or normal) by estimating the odds ratio with $95 \%$ confidence interval (CI). Variables were considered significant at a p-value $\leq 0.05$. 
Statistical analysis was performed using SPSS version 11.5 software.

\section{Results}

\section{Characteristics of study participants}

A high percentage prevalence of pre-hypertension was observed in the studied population, 33.7\% (95\% confidence interval [CI]; 30.6\%-36.8\%). Pre-hypertension was higher in men than in women (36.4\%; CI, 31.7\%-41/1\% and $31.4 \%$; CI, 27.3\%-35.5\%) but there was no significant difference in the percentages $(\mathrm{p}>0.05)$. The prevalence rate of hypertension among all subjects was $35.4 \%$. However, no significant difference was found in the percentages of the prevalence rate of hypertension in male (35.1\%) and female (35.5\%) participants ( $\mathrm{p}>0.05)$.

Figure 1 illustrates an age-group specific pattern concerning the pre-hypertension prevalence rate. A steady decline in the prevalence of pre-hypertension is apparent with an exception for the 50-59 age group $(\mathrm{p}=0.025)$.

In Table 1 are presented the epidemiological characteristics of the study participants as blood pressure groups. It appears that fasting serum glucose, triglyceride and BMI mean values were higher in pre-hypertensive group than in the normotensive group, respectively $(\mathrm{p}=0.013$; $\mathrm{p}=0.002 ; \mathrm{p}<0.001)$.

In Table 2 we can observe that the pre-hypertensive group exhibited higher prevalence of overweight $(\mathrm{p}<$ 0.001 ) and its subjects had 1.77 times increased probability of being overweight than their normotensive counterparts. Furthermore the preh-ypertensive group had higher prevalence of diabetes mellitus, total hypercholesterolemia, and obesity but there was no statistical difference in percentages $(p>0.05)$. In addition, fewer pre-hypertensive subjects reported smoking than their normotensive counterparts (12.3\% vs $18.8 \%$; $\mathrm{p}=0.031)$.

In Table 3 appear the percentages of subjects exhibiting $0,1,2,3,4$ or more additional cardiovascular risk

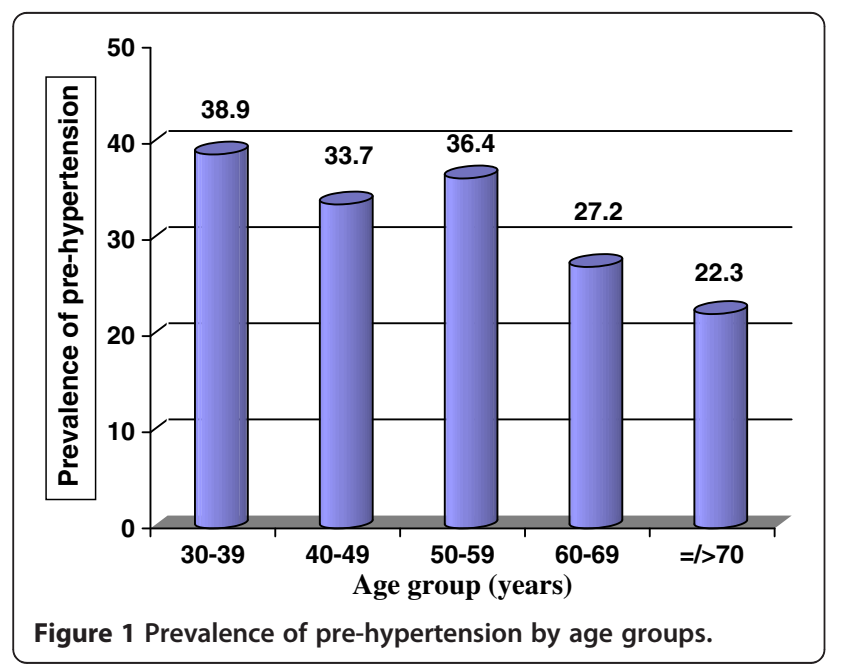

factors according to their blood pressure indices. 7.6\% and $7.2 \%$ of the normotensive group and $16.3 \%$ and $9.3 \%$ of the pre-hypertensive group exhibited three and $\geq 4$ additional cardiovascular risk factors, respectively. The corresponding percentages for the hypertensive group were $23.5 \%$ and $17.4 \%$, respectively.

\section{Multivariate logistic regression}

In Table 4 the results of multivariate logistic regression analysis showed that obesity and overweight were the most powerful predictors of pre-hypertension, with an odds ratio (OR) of 2.74 (95\% CI, 1.62 to $4.62, \mathrm{p}<0.001$ ) and 2.56 (95\% CI, 1.74 to $3.77, \mathrm{p}<0.001$ ), followed by male gender (OR, 1.89; 95\% CI, 1.29 to $2.81, \mathrm{p}=0.002$ ). On the contrary, age $(\mathrm{p}=0.002)$ and smoking $(\mathrm{p}=0.003)$ had an inverse effect on pre-hypertension.

\section{Discussion}

Over the last years increased pre-hypertension rates have been observed and well documented worldwide. However, this area is still not fully investigated. Therefore, the purpose of this study was to further explore this issue focusing on a population-based sample of adults in south Iran.

The results revealed that nearly one third of our population was classified as pre-hypertensive. A higher percentage of the male population - compared to the female population - was found to exhibit prehypertension, without, however, significant difference in the percentages. Furthermore, it was also found that obesity and overweight had the strongest association with pre-hypertension but, surprisingly, age and smoking had an inverse effect on pre-hypertension. In addition, it was disclosed that subjects with pre-hypertension had multiple additional cardiovascular risk factors when compared to those with normal blood pressure.

Nontheless, the prevalence of pre-hypertension in the present study (33.7\%) was higher when compared with the prevalence estimates reported in Jamaica (31\%), in Turkey (14.5\%), in Canada (22.0\%), in Nigeria (24.8\%), in Tailand (32.8\%) and in Japan (33.0\%). On the contrary, the prehypertension estimate in our sample was lower when compared with the results reported from Taiwan (35.8\%), U.S.A. (36.3\%) and China (38.4\% and $44.1 \%)$ $[6,7,13,17-23]$. However, the present findings contradict the Jamaica Study's gender specific pattern whereby men (35.0\%) rather than women (25.0\%) exhibited higher percentages of pre-hypertension [6].

Additionally, it was detected that the prevalence of prehypertension was higher among younger age groups. This finding is in line with the published data from China [7] and Japan [24], but contradicts the results reported in Iran [25] and Nigeria [18] showing an 
Table 1 Subjects characteristics by blood pressure group. Figures are Mean ( \pm SD)

\begin{tabular}{|c|c|c|c|c|c|}
\hline Variable & Normotension & pre-hypertension & $\mathrm{p}^{*}$ & hypertension & $\mathbf{p}^{* *}$ \\
\hline Age (years) & $43.8 \pm 10.0$ & $48.1 \pm 12.8$ & $<0.001$ & $57.1 \pm 13.4<0.001$ & $<0.001$ \\
\hline Glucose $^{\#}$ & $88.9 \pm 27.1$ & $94.8 \pm 29.5$ & 0.013 & $109.4 \pm 50.7$ & $<0.001$ \\
\hline Cholesterol $^{\#}$ & $184.9 \pm 41.2$ & $188.7 \pm 37.9$ & 0.225 & $199.0 \pm 44.5$ & $<0.001$ \\
\hline LDL cholesterol ${ }^{\#}$ & $112.7 \pm 28.6$ & $113.6 \pm 30.1$ & 0.704 & $119.8 \pm 35.6$ & 0.008 \\
\hline HDL cholesterol" ${ }^{\#}$ & $47.4 \pm 10.8$ & $47.5 \pm 10.3$ & 0.851 & $48.5 \pm 10.5$ & 0.195 \\
\hline Triglyceride ${ }^{\#}$ & $121.9 \pm 73.2$ & $144.7 \pm 98.6$ & 0.002 & $155.9 \pm 88.8$ & $<0.001$ \\
\hline $\mathrm{BMl}, \mathrm{kg} / \mathrm{m}^{2}$ & $25.3 \pm 4.3$ & $26.8 \pm 4.3$ & $<0.001$ & $26.9 \pm 4.4$ & $<0.001$ \\
\hline
\end{tabular}

* Pre-hypertensive to normotensive subjects comparisons.

** Hypertension to normotensive subjects comparisons.

\# mg/dl.

opposite pattern, with a little decrease in persons above 60 years old.

The present study also complements previous reports from Iran demonstrating high prevalence of prehypertension. Indeed, results from the Nationwide Survey in Iran between 2004-2005 revealed a high incidence of pre-hypertension in both sexes aged 25-65, i.e., $59.6 \%$ in men and $44.5 \%$ in women, respectively [25]. Similar results were also reported by Sahebi et al. [26] where $37.2 \%$ of hospital staff in Shiraz, Iran, aged 19 years and over, found to be pre-hypertensive.

However, social and cultural differences, the subject's characteristics, the age span as well as the methodology used, may account for the observed discrepancies among the previous mentioned studies. Nonetheless, although direct comparisons with other studies are not possible, it is rather self-evident that the prevalence of prehypertension is high in both developed and developing countries and in eastern and western populations and, therefore, needs further in depth clarification.

Another main finding revealed that pre-hypertension was associated with an increased prevalence of other cardiovascular risk factors such as age, sex, overweight and obesity. The association of pre-hypertension with multiple risk factors for cardiovascular disease has been described in the Jamaican population [6]. Indeed, the prevalence of hypercholesterolemia, diabetes mellitus, overweight and obesity was found to be greater among persons with pre-hypertension compared to persons who were normotensive in Jamaican population [6]. A number of other studies suggested that persons with pre-hypertension were more likely to have a higher BMI, total cholesterol, triglyceride, higher LDL cholesterol and lower HDL cholesterol level of blood, impaired glucose tolerance, obesity and older age than persons who had normal blood pressure $[3,17,18,27]$. This clustering of cardiovascular disease risk factors among persons with pre-hypertension suggest the importance of screening for other cardiovascular risk factors in persons who are classified as pre-hypertensive.

Our results confirmed that obesity and overweight are major determinants of pre-hypertension. Similar findings were also found in the Chinese survey, in Japan and in a rural Taiwanese adult population [7,20,24,28-31]. Additionally, in Sahebi et al. [26] study, the association between pre-hypertension with obesity and overweight was, also, confirmed.

Table 2 Prevalence of individual cardiovascular risk factors (\%) by blood pressure group

\begin{tabular}{|c|c|c|c|c|c|}
\hline Variable & normal & pre-HTN & $\mathrm{RR}^{*}(95 \% \mathrm{Cl})$ & HTN & $\mathrm{RR}^{\#}(95 \% \mathrm{Cl})$ \\
\hline Sex (male,\%) & 41.7 & 49.0 & $1.34(0.97-1.87)$ & 45.1 & $1.15(0.83-1.59)$ \\
\hline Smoking & 18.8 & 12.3 & $0.6(0.38-0.96)$ & 8.6 & $0.40(0.24-0.66)$ \\
\hline Diabetes mellitus & 4.7 & 8.7 & $1.92(0.97-3.81)$ & 20.6 & $5.26(2.83-9.78)$ \\
\hline Total & 7.6 & 10.0 & $1.35(0.75-2.42)$ & 16.5 & $2.40(1.40-4.10)$ \\
\hline \multicolumn{6}{|l|}{ Hypercholesterolemia } \\
\hline High LDL level & 5.4 & 6.3 & $1.18(0.58-2.36)$ & 12.7 & $2.53(1.36-4.69)$ \\
\hline Low HDL level & 9.1 & 9.0 & $0.99(0.56-1.76)$ & 7.3 & $0.79(0.43-1.42) 0$ \\
\hline Hypertriglyceridemia & 11.6 & 16.7 & $1.52(0.95-2.46)$ & 24.4 & $2.46(1.57-3.86)$ \\
\hline Overweight & 35.1 & 49.0 & $2.15(1.53-3.01)$ & 44.1 & $2.0(1.43-2.78)$ \\
\hline Obesity & 13.8 & 18.3 & $1.40(0.89-2.20)$ & 21.6 & $1.72(1.11-2.66)$ \\
\hline
\end{tabular}

HTN indicates hypertension; RR, risk ratio.

* Ratio of pre-hypertension group to normotensive group.

\# Ratio of hypertension group to normotensive group. 


\section{Table 3 Clustering ${ }^{1}$ of Cardiovascular risk factors by blood pressure group.}

\begin{tabular}{|c|c|c|c|c|}
\hline $\begin{array}{l}\text { Number of additional } \\
\text { Risk factors }\end{array}$ & $\begin{array}{l}\text { normal } \\
(\%)\end{array}$ & $\begin{array}{l}\text { pre-HTN } \\
(\%)\end{array}$ & $\begin{array}{l}\text { HTN } \\
(\%)\end{array}$ & $p$-value \\
\hline 0 & 21.0 & 8.3 & 1.9 & $<0.001$ \\
\hline 1 & 38.8 & 37.7 & 22.9 & $<0.001$ \\
\hline 2 & 25.4 & 28.4 & 34.3 & $<0.051$ \\
\hline 3 & 7.6 & 16.3 & 23.5 & $<0.001$ \\
\hline$\geq 4$ & 7.2 & 9.3 & 17.4 & $<0.001$ \\
\hline
\end{tabular}

Finally, in our study, the odds of smoking had reverse significant association among pre-hypertensive subjects when compared to normotensive persons. This finding is in line with other studies $[6,26,32]$, but contradict Kawamoto et al. [24] findings who reported a higher smoking rate in pre-hypertensive subjects when compared with normotensive subjects.

\section{Limitations}

The two BP measurements in one day that was used for our subject classification in the various blood pressure categories, the higher percentage of the female population compared to the male one, lack of data on habitual physical activity and the absence of dietary data could be some limitations that restricted our scientific contribution to the area.

\section{Conclusions}

In conclusion and within the study's limitations, overweight and obesity were found to be decisively associated with the high prevalence of pre-hypertension in

\section{Table 4 Determinants of prehypertension vs normal blood pressure from multivariable logistic regression model}

\begin{tabular}{llll}
\hline Variable & OR $^{*}$ & $\mathbf{9 5 \%} \mathbf{C l}$ & p-value \\
\hline Obesity & 2.74 & $1.62-4.62$ & $<0.001$ \\
Overweight & 2.56 & $1.74-3.78$ & $<0.001$ \\
Smoking & 0.45 & $0.26-0.76$ & 0.003 \\
Male sex & 1.89 & $1.27-2.81$ & 0.002 \\
Age (year) & 0.96 & $0.95-0.98$ & $<0.001$ \\
Diabetes mellitus & 1.36 & $0.66-2.82$ & 0.398 \\
Total & 1.07 & $0.56-2.03$ & 0.833 \\
Hypercholesterolemia & & & \\
High LDL level & 0.81 & $0.29-2.23$ & 0.694 \\
Low HDL level & 0.92 & $0.63-1.32$ & 0.65 \\
Hypertriglyceridemia & 1.28 & $0.78-2.12$ & 0.326 \\
\hline *OR= Odds Ratio. & & &
\end{tabular}

${ }^{*} \mathrm{OR}=$ Odds Ratio.
Iranian adults. Additionally, a causative relationship between pre-hypertension and clustering of cardiovascular risk factors was documented. Therefore, primary preventive strategies should focus on reducing overweight and obesity if the future pre-hypertension risk in Iranian population is to be reduced.

\begin{abstract}
Abbreviations
BMI: Body mass index; Cl: Confidence interval; DBP: Diastolic blood pressure; HDL-C: High density lipoprotein cholesterol; IHPS: Iranian health profile survey; JNC7: Seventh report of joint national committee; LDL-C: Low density lipoprotein cholesterol; OR: Odds ratio; SBP: Systolic blood pressure; SD: Standard deviation.
\end{abstract}

Competing interest

The authors declare that they have no competing interest.

\section{Authors' contributions}

RK and SM was involved in data collection, performed data analysis. RK wrote manuscript. SM helped revised manuscript. All authors read and approved the final manuscript.

\section{Acknowledgements}

The authors would like to acknowledge staffs from urban health centers and chemistry laboratory of Peymaniah hospital. We also would like to thank to the persons who participated to this study. The study was funded by the Research Council of Jahrom University of Medical Sciences.

\section{Author details}

'Department of Social Medicine, Jahom University of Medical Sciences, Jahrom, Iran. ${ }^{2}$ Department of Internal medicine, Jahom University of Medical Sciences, Motahhari Avenue, Jahrom, Iran.

Received: 3 January 2012 Accepted: 18 June 2012

Published: 28 July 2012

\section{References}

1. Zhou Z, Hu D, Chen J: Association between obesity indices and blood pressure or hypertension: which index is the best? Public Health Nutrition 2008, 12(8):1061-1071.

2. Uhernik AL, Erceg M, Milanovic SM: Association of BMI and nutritional habits with hypertension in the adult population of Croatia. Public Health Nutrition 2008, 12(1):97-104.

3. Jimenez-Corona A, Lopez-Ridaura R, Stern MP, Gonzalez-Villalpando C: Risk of progression to hypertension in a low-income Mexican population with prehypertension and normal blood pressure. Am J Hypertens 2007, 20(9):929-936.

4. Haghdoost AA, Sadeghirad B, Rezazadehkermani M: Epidemiology and Heterogeneity of Hypertension in Iran: A Systematic Review. Arch Iranian Med 2008, 11(4):444-452

5. Hadi N, Rostami-Gooran N: Determinant factors of medication compliance in hypertensive patients of Shiraz, Iran. Archives of Iranian Medicine 2004, 7(4):292-296.

6. Ferguson TS, Younger NO, Tulloch-Reid MK, Wright MBL, Ward EM, Ashley DE, Wilks R: Prevalence of prehypertension and its relationship to risk factors for cardiovascular disease in Jamaica: Analysis from a cross-sectional survey. BMC Cardiovascular Disorder 2008, 8(20):20.

7. Pang W, Sun Z, Zheng L, Li J, Zhang X, Liu S, Xu C, Li J, Hu D, Sun Y: Body mass index and the prevalence of prehypertension and hypertension in a Chinese rural population. Intern Med 2008, 47(10):893-897.

8. Lewington S, Clarke R, Qizillbash N, Peto R, Collins R: Age-specific relevance of usual blood pressure to vascular mortality: a meta-analysis of individual data for one million adults in 61 prospective studies. Lancet 2002, 360:1903-1913.

9. Vasan RS, Larson MG, Leip EP, Kannel WP, Levy D: Assessment of frequency of progression to hypertension in non-hypertensive participants in Framingham Heart Survey: acohort study. Lancet 2001, 358:1682-1686,

10. Lorenzo C, Aung K, Stern MP, Haffner SM: Pulse pressure, prehypertension, and mortality: the San Antonio heart study. Am J Hypertens 2009, 22(11):1219-1226. 
11. Gu D, Chen J, Wu X, Duan X, Jones DW, Huang JF, Chen CS, Chen JC, Kelly TN, Whelton PK, He J: Prehypertension and risk of cardiovascular disease in Chinese adults. $J$ Hypertens 2009, 27(4):721-729.

12. Ishikawa Y, Ishikawa J, Ishikawa S, Kajii E, Schwartz JE, Pickering TG, Kario K. Prehypertension and the risk for cardiovascular disease in the Japanese general population: the Jichi Medical School Cohort Study. J Hypertens 2010, 28(8):1630-1637.

13. Godwin M, Pike A, Kirby A, Jewer C, Murphy L: Prehypertension and hypertension in a primary care practice. Can Fam Physician 2008 54(10):1418-1423.

14. The Seventh Report of the Joint National Committee on Prevention, Detection, Evaluation, and Treatment of High Blood Pressure (JNC 7): The Guidelines. US Department of Health and Human Services, National Heart, Lung, and Blood Institute.: ; Available at http://www.nhlbi.nih.gov/guidelines/ hypertension/ Accessed Jul 5, 2008.

15. American Diabetes Association: Diagnosis and classification of diabetes mellitus. Diabetes Care 2006, 29:S43-S48.

16. Expert Panel on Detection: Evaluation and Treatment of High Blood Cholesterol in Adults. Executive Summary of The Third Report of The National Cholesterol Education Program (NCEP) Expert Panel on Detection, Evaluation And Treatment of High Blood Cholesterol In Adults (Adult Treatment Panel III). JAMA 2011, 285(19):2486-2497.

17. Liu LK LNP, Chen LK, Hwang SJ, Chiou ST: Prehypertension Among Middle-Aged and Eiderly People in Taiwan: A Five-Year Follow-Up. J Atherosclr Thromb 2010, 17:189-194.

18. Isezuo SA, Sabir AA, Ohwovorilole AE, Fasanmade OA: Prevalence, associated factors and relationship between prehypertension and hypertension: a study of two ethnic African populations in Northern Nigeria. J Hum Hypertens 2011, 25:224-230.

19. Gupta AK, McGlone M, Greenway FL, Johnson WD: Prehypertension in disease-free adults: a marker for an adverse cardiometabolic risk profile. Hypertens Res 2010, 33:905-910.

20. Ishikawa Y, Ishikawa J, Ishikawa S, Kayaba K, Nakamura Y, Shimada K, Kajii E, Pickering TG, Kario K: Prevalence and determinants of prehypertension in a Japanese general population: the Jichi Medical School Cohort Study. Hypertens Res 2008, 31(7):1323-1330.

21. Erem C, Hacihasanoglu A, Kocak M, Deger O, Topbas M: Prevalence of prehypertension and hypertension and associated risk factors among Turkish adults: Trabzon Hypertension Study. J Public Health (Oxf) 2009, 31(1):47-58

22. Zhang $M$, Batu B, Tong W, Li H, Lin Z, Li Y, Zhang X, Zhang Y: Prehypertension and cardiovascular risk factor clustering among Mongolian population in rural and animal husbandry area, Inner Mongolia, China. Circ J 2009, 73(8):1437-1441.

23. Aekplakorn W, Abbott-Klafter J, Khonputsa P, Tatsanavivat P, Chongsuvivatwong V, Chariyalertsak S, Sangwatanaroj S, Tiptaradol S, Lim SS: Prevalence and management of prehypertension and hypertension by geographic regions of Thailand: the Third National Health Examination Survey, 2004. J Hypertens 2008, 26(2):191-198.

24. Kawamoto R, Kohara K, Tabara Y, Miki T: High prevalence of prehypertension is associated with the increased body mass index in community-dwelling Japanese. Tohoku J Exp Med 2008, 216(4):353-361.

25. Janghorbani M, Amini M, Gouya MM, Delavari A, Alikhani S, Mahdavi A: Nationwide survey of prevalence and risk factors of prehypertension and hypertension in Iranian adults. J Hypertens 2008, 26(3):419-426.

26. Sahebi L, Vahidi RG, Mousavi SH: prevalence of hypertension and associated variables in hospital staff in Iran. Acta Med Sal 2010, 39(1):6-13.

27. Nah EH, Kim HC: Comparison of cardiovascular risk factors between normotension and prehypertension. Korean J Lab Med 2007 27(5):377-381.

28. Ganguly SS, Al-Shafaee ML, Bhargava K, Duttagupta KK: Prevalence of prehypertension and associated cardiovascular risk profiles among prediabetic Omani adults. BMC Publ Health 2008, 8:108-114.

29. Agyemang C, van Valkengoed I, van den Born BJ, Stronks K: Prevalence and determinants of prehypertension among African Surinamese, Hindustani Surinamese, and White Dutch in Amsterdam, the Netherlands: the SUNSET study. Eur J Cardiovasc Prev Rehabil 2007, 14(6):775-781.

30. Greenlund KJ, Daviglus ML, Croft JB: Differences in healthy lifestyle characteristics between adults with prehypertension and normal blood pressure. J Hypertens 2009, 27(5):955-962.
31. Doll S, Paccaud F, Bovet P, Burnier M, Wietlisbach V: Body mass index, abdominal adiposity and blood pressure: consistency of their association across developing and developed countries. Int J Obes 2002, 26:48-57.

32. Agyemang C, Owusu-Dabo E: Prehypertension in the Ashanti region of Ghana, West Africa: an opportunity for early prevention of clinical hypertension. Public Health 2008, 122(1):19-24.

doi:10.1186/1756-0500-5-386

Cite this article as: Rahmanian and Shojaie: The prevalence of pre-hypertension and its association to established cardiovascular risk factors in south of Iran. BMC Research Notes 2012 5:386.

\section{Submit your next manuscript to BioMed Central and take full advantage of:}

- Convenient online submission

- Thorough peer review

- No space constraints or color figure charges

- Immediate publication on acceptance

- Inclusion in PubMed, CAS, Scopus and Google Scholar

- Research which is freely available for redistribution

Submit your manuscript at www.biomedcentral.com/submit
C) Biomed Central 